Working Paper/Document de travail 2013-6

\title{
To Link or Not To Link? Netting and Exposures Between Central Counterparties
}

by Stacey Anderson, Jean-Philippe Dion and Hector Perez Saiz 
Bank of Canada Working Paper 2013-6

March 2013

\title{
To Link or Not To Link? Netting and Exposures Between Central Counterparties
}

by

\author{
Stacey Anderson, ${ }^{1}$ Jean-Philippe Dion ${ }^{2}$ and Hector Perez Saiz ${ }^{1}$ \\ ${ }^{1}$ Financial Stability Department \\ 2Financial Markets Department \\ Bank of Canada \\ Ottawa, Ontario, Canada K1A 0G9 \\ sanderson@bankofcanada.ca \\ jpdion@bankofcanada.ca \\ hperezsaiz@bankofcanada.ca
}




\section{Acknowledgements}

We thank for comments and suggestions Jason Allen, Toni Gravelle, Stéphane Lavoie, Darcey McVanel, Thomas Nellen, Carol Ann Northcott, Joshua Slive, Haoxiang Zhu and participants of seminars at the Bank of Canada. 


\begin{abstract}
This paper provides a framework to compare linked and unlinked CCP configurations in terms of total netting achieved by market participants and the total system default exposures that exist between participants and CCPs. A total system perspective, taking both market participant and CCP exposures into account, is required to answer an important policy question faced by some smaller jurisdictions: whether or not to consider linking a domestic CCP with one or more offshore CCPs. Generally, a single global CCP results in the lowest total system exposure as it allows for multilateral netting across all participants while avoiding the creation of inter-CCP exposures via links. However, global clearing may not be appropriate for all markets. Using a two country model, with a global CCP serving both markets and a local CCP clearing only domestic country participants' transactions, we show that establishing links between two CCPs leads to higher exposures for the domestic CCP and can result in a decrease in overall netting efficiency and higher total system exposures when the number of participants at the local CCP is small relative to the number of participants at the global CCP. As the relative weight applied by decision makers to CCP exposures as compared to market participants' exposures increases, so does the number of domestic participants required to make the linked case preferred from a total system perspective. Our results imply that the establishment of a link between a small domestic CCP and a larger global CCP is unlikely to be desirable from a total system perspective in the majority of cases.
\end{abstract}

JEL classification: G230, G18

Bank classification: Payment, clearing, and settlement systems

\title{
Résumé
}

Dans leur étude, les auteurs proposent un cadre permettant de comparer des modèles de compensation par contrepartie centrale (CC) selon que ces entités sont - ou non interreliées, en évaluant, d'une part, la réduction des positions nettes obtenue par les participants au marché et, d'autre part, la totalité des expositions au risque de défaut présentes à l'échelle du système, qui existent entre CC et participants. Une perspective systémique globale, qui prend en compte aussi bien les expositions des participants que celles des CC, est requise pour répondre à une question stratégique importante que se posent certains petits pays quant à l'opportunité de mettre en place des liens entre une CC nationale et une ou plusieurs CC étrangères. De manière générale, les expositions totales d'un système sont à leur niveau le plus bas quand le marché est desservi par une seule CC d'envergure mondiale, puisque celle-ci assure la compensation multilatérale des opérations entre tous les participants sans que des expositions ne soient créées entre les CC par l'entremise de liens. Pour autant, la compensation par une CC mondiale n'est pas justifiée pour tous les marchés. À l'aide d'un modèle comprenant deux pays, une CC mondiale desservant les deux marchés et une CC nationale compensant uniquement les transactions des participants de son marché, les auteurs montrent que la création de liens 
entre les deux CC accroît les expositions de la CC nationale et peut amoindrir l'efficience globale de la réduction des positions nettes et entraîner une augmentation des expositions totales au sein du système lorsque cette CC compte un nombre de participants relativement plus faible que la CC mondiale. À mesure qu'on accroît la pondération appliquée par les décideurs publics aux expositions des CC comparativement à celles des participants, on observe également une hausse du nombre de participants locaux nécessaire pour que l'établissement de liens entre CC offre la solution la plus avantageuse dans une optique systémique globale. Les résultats impliquent que, dans la majorité des cas, la création de liens entre une petite CC nationale et une CC mondiale de plus grande envergure n'est probablement pas souhaitable dans une perspective systémique globale.

Classification JEL : G230, G18

Classification de la Banque : Systèmes de paiement, de compensation et de règlement 


\section{Introduction}

In an effort to comply with the G20 commitment to clear all standardized over-the-counter (OTC) derivatives through central counterparties (CCPs) by the end of 2012, several jurisdictions have considered creating a domestic CCP that clears trades for local market participants. However, for many products, large global infrastructures already offer similar clearing capabilities to both eligible local participants and eligible foreign dealers. As a result, local regulators must consider the trade-offs between establishing clearing capabilities locally and allowing domestic market participants to clear at global CCPs. ${ }^{1}$

A potential alternative to having local market participants clear offshore or split their portfolios between multiple CCPs is to link a domestic CCP to one or more offshore CCPs. Links allow counterparties to each clear at a different CCP, with an inter-CCP contract being created to offset these exposures. Links allow members to multilaterally net offsetting long and short positions across the combined membership of both CCPs and thereby reduce their exposures. However, this comes at the cost of creating a new exposure due to the link between the CCPs. Therefore, regulators should have a framework for weighting the netting gains achieved by market participants against the new default exposures created by a link.

This paper offers a framework for analyzing the relative benefits of linked and unlinked CCP configurations. We employ a similar measure of netting efficiency as Duffie and Zhu (2011) (who consider the average, across participants, of expected counterparty exposures after netting), however we extend their definition by introducing the concept of "total system exposure". Total system exposure comprises not only each participant's expected exposure but also, for configurations where a CCP is present, each CCP's expected exposure to participants and to linked CCPs. This is an important extension because by including CCP exposures alongside those of participants in our measure, we can analyze more complex linked structures where market participants' exposures may decline due to increased netting while new risks are created through inter-CCP exposures.

Generally, a single global CCP results in the lowest total system exposure as it allows for multilateral netting across all participants while avoiding the creation of inter-CCP exposures via links. However, global clearing may not be appropriate for all markets and instead, links could be considered between local CCPs. However, using a simple two country model and our measure of total system exposures, we show that when the number of domestic clearing members is small, a model with two unlinked CCPs, where domestic participants clear trades with other domestic participants locally and with foreign participants offshore,

\footnotetext{
${ }^{1}$ For example, the trade-offs between local and global clearing are discussed, within the context of the Canadian interest rate swap market, by Chande et al. (2012).
} 
is a more efficient configuration than establishing a link between the two CCPs. Under these conditions, the netting gains achieved by domestic market participants through the establishment of a link do not compensate for the additional exposures taken on by the domestic CCP. However, as the number of domestic clearing members increases, a linked CCP configuration becomes more attractive from the perspective of total system exposures. ${ }^{2}$

From a regulatory perspective, a CCP's exposures to participants or other CCPs and conversely a participant's exposures to CCPs may not be seen as equivalent. A CCP regulator may be particularly concerned about the central role that such infrastructure plays in financial markets and with the size of its outward-facing exposures, particularly if this exposure is concentrated to a linked CCP. A prudential regulator on the other hand may favour efficient netting for participants and may wish to minimize market participants' uncollateralised exposures to a CCP default. For these reasons, total system exposure in our model is also dependent on the relative importance assigned to CCP exposures compared to clearing member exposures by a given regulator. As the relative importance assigned to CCP exposures (policy parameter $\omega$ in our framework) decreases, the case for establishing a link becomes more compelling. At the limit, if no importance is assigned to CCP exposures, a CCP configuration with a clearing link is seen as equivalent to a single global CCP.

These results help describe the trade-offs that both regulators and infrastructure providers face when considering the establishment of inter-CCP links. As we show, the relative number of market participants in each country is a critical determinant of which configuration results in the lowest level of default exposures for each CCP, and therefore should be preferred by CCPs themselves and arise naturally in the market for clearing services.

At the time of writing, we are unaware of any research that focuses specifically on the trade-off between CCPs' exposures and the level of netting achieved by participants in different clearing configurations. This paper approaches the issue with a focus on systemic risk, discussing default exposures from both market participant and CCP perspectives, while highlighting the role that CCP size plays in determining the efficiency of a linked clearing configuration.

\section{Background on CCP links}

A CCP is a financial market infrastructure that interposes itself between the two counterparties to a trade in order to mitigate credit risk. Credit risk can arise in bilateral derivatives

\footnotetext{
${ }^{2}$ The relative size of membership at each CCP is considered to be exogenous in our model and is an important consideration since countries considering local clearing infrastructure may not be home to the largest number of market participants.
} 
contracts if a counterparty to a contract were to default on their obligations, leaving the other party to replace the contract at current market value. By managing and mitigating credit risk, CCPs have the potential to reduce systemic risk and to support a market's ability to remain continuously open even in times of stress (Chande et al. (2010)).

Central clearing of derivatives has other specific advantages. It reduces the web of opaque bilateral exposures that exist in OTC markets when participants novate their trades to a CCP, which becomes buyer to every seller and seller to every buyer. CCPs also promote more uniform risk management by collecting collateral from participants and by defining ex-ante procedures for the handling and mutualisation of a participant default. Finally, through multilateral netting the CCP can reduce total counterparty exposures in OTC markets.

The current landscape for OTC derivatives clearing is dominated by a few large CCPs, each clearing specific asset classes for an international membership base. However, some regulators may have concerns with allowing local market participants to clear on offshore infrastructure. Alternatively, local infrastructure providers may have a commercial interest in offering clearing services tailored to local market participants. Both of these situations could lead to the creation of a local CCP. Domestic CCPs have a number of advantages as elaborated in Slive et al. (2011) - such as the improved possibility of clearing important local products that are not cleared offshore, of providing local regulators with direct oversight of the CCP and of allowing direct access to smaller high quality market participants - but their introduction comes at a cost in terms of lost netting benefits. With multiple CCPs clearing the same asset class, the volume of trades that flow through any single infrastructure is lower than if only one CCP cleared all products. As a result, the level of netting achieved by participants at any single CCP decreases and default exposures increase.

Establishing links between CCPs in different jurisdictions could allow any of the above mentioned lost netting opportunities to be regained. Links are contractual agreements whereby two CCPs agree to multilaterally net exposures across their combined membership. Market participants, through their access to a linked domestic CCP, would therefore net exposures across a broader range of counterparties. The creation of links between CCPs does, however, pose challenges. By creating credit exposures between CCPs themselves, links create new channels for risk propagation. If a linked CCP were to default, the surviving CCP would need to fulfill the contractual obligations of cleared contracts to its members. Although not the subject of this paper, links may also create oversight challenges due to additional operational, legal and liquidity risks and increase complexity while reducing the transparency of exposures in the clearing system (CGFS (2011)).

As a result of these challenges, only a handful of links have successfully been established 
between CCPs and most of these are limited to the cash equities market, with a well-known example being the link that exists between LCH.Clearnet and Swiss CCP X-Clear. The slow propagation of links, particularly for product classes such as OTC derivatives, where exposures can be large, is an indication that the challenges inherent in creating links are impacting the willingness of both regulators and infrastructure providers to move forward with these agreements. By examining the balance of pre and post-link exposures in our analytical framework we identify conditions under which regulators should give serious consideration to linking CCPs.

\section{Related Literature}

There is a growing literature that studies the benefits from central clearing. For example, Koeppl and Monnet (2010) study the benefits of novation and central clearing to diversify counterparty risk. Acharya and Bisin (2011) emphasize lack of information about the risks taken on by counterparties to contracts and show how a CCP eliminates this information externality.

Our work is related to the literature that highlights the multilateral netting benefits of CCP clearing. Duffie and Zhu (2011) provide a theoretical model and analytical solutions to show that it is better to have a CCP that jointly clears multiple asset classes than to have individual CCPs each clearing their own respective products. Jackson and Manning (2007) introduce a simulation methodology that evaluates the cost and risk implications of various clearing arrangements: bilateral trades, clearing through a single CCP and ring clearing. Their chosen metrics are the magnitude and distribution of replacement cost losses amongst participants following a default in each clearing model.

There are few papers that study linked CCP configurations. Renault (2010) models seven clearing setups (one of which includes a link between CCPs) when investigating concentration risks in the clearing of a single asset between two regions and in two currencies. The focus is on inducing the default of the $\mathrm{CCP}(\mathrm{s})$ through the simultaneous default of several banks and large price movements in the underlying asset (a combined market and banking crisis). The chosen metric is the average number of affected trades if the $\mathrm{CCP}(\mathrm{s})$ default. Renault shows that the clearing set-up that is most robust depends on the nature and severity of the (banking) crisis as well as other factors such as the size of the clearing funds, the level of market integration and the number of participating banks.

Mägerle and Nellen (2011) consider the risk management (collateralization) of financial exposures resulting from links between CCPs. They show that a clearing system with multiple interoperating CCPs can achieve the same netting efficiency as a clearing system with 
a single CCP and then compare the collateralization of inter-CCP exposures under the current model for European cash equity CCPs with the new European guidelines and find that neither is optimal. ${ }^{3}$ Relative to our framework, they model collateralization of exposures between linked CCPs but do not examine how the balance of market participant exposures and CCP exposures changes with the number of market participants in each country, or how regulatory preferences could impact the decision to link.

\section{Methodology}

The existing literature clearly sets out that introducing more than one CCP for a single asset class leads to sub-optimal netting for market participants who centrally clear this product. Linking CCPs can restore some of the netting benefits lost when moving away from a single CCP structure. We propose an analytical framework to quantify the reduction in default exposures gained through netting in a linked CCP model and weigh these against the default exposures created between CCPs. Our analysis requires that we look beyond a single CCP or market participant's exposures and introduce the concept of total system exposures that includes the exposures faced by CCPs and by clearing members.

Our analysis focuses on one asset class and four clearing models. In our model, there are two countries: the domestic market (DOM) and the offshore, or foreign market (FOR). Two sets of agents exist in the OTC market, domestic market participants and foreign participants. Our base model is a bilateral clearing environment where each participant in the OTC market trades with each of the other participants. Next, we introduce a clearing model where all participants in the OTC market clear through a single "global" CCP. This is followed by a model where domestic market participants are members of both CCPs, clearing trades with other domestic members locally (since all domestic participants are members of the local CCP) and with foreign counterparties at an offshore CCP (since domestic participants are members of the foreign CCP for trades with foreign counterparties). In this unlinked model with two CCPs, participants cannot freely choose which CCP to clear at and this is instead determined by the location of their counterparty. Finally, we model the establishment of a link between the domestic CCP and the offshore CCP. The link allows domestic participants to centrally clear transactions entered into with both domestic and foreign participants, while being members of only the domestic CCP.

\footnotetext{
${ }^{3}$ The current model involves the rehypothecation of clearing member collateral across links, while the new European guidelines require cross-CCP exposures to be fully collateralised and to be covered by extra collateral that is funded via financial resources other than the members' ordinary margin contributions to collateralise exposures vis-a-vis the CCPs.
} 
In order to compare the different clearing models, we examine the total default exposures between market participants and CCPs, beginning with the concept of "netting efficiency" as introduced by Duffie and Zhu (2011): the average, across participants, of total expected counterparty exposures, after netting, but before collateral.

Our model must also incorporate the impact of links, and therefore we deal with two types of exposures: exposures faced by CCPs (either to their members or to another CCP) and exposures faced by market participants (either to other market participants or to the CCPs themselves). We introduce the concept of total system exposures, which is based on a sum rather than an average of market participant and CCP default exposures, to compare different clearing models. ${ }^{4}$

Definition 1 The expected total system exposure of a system comprising a set of market participants and zero or more CCPs is the weighted sum of each market participant's expected positive exposure to each other participant and each CCP and each CCP's expected positive exposure to each market participant and each other $C C P{ }^{5}$

We assume that all contracts in the system have zero market value at origination and that exposures result from movements in market prices prior to the exchange of variation margin. Such a system would be equivalent to one where variation margin were exchange between participants on a daily basis.

Expected total system exposure takes into account only the expected positive exposure on each side of the trade. By summing only positive exposures, we are avoiding potential issues of double counting losses in a default by recognising that a potential movement in contract value will benefit one counterparty to a trade while leading to a loss for the other. A loss would be incurred only if a participant's counterparty were to default while the contract had positive value for the survivor. Summing the expected positive exposures from each market participant or CCP perspective also allows us to apply different weights to these sets of exposures.

We parameterize the relative importance of CCP exposures to participants and linked $\mathrm{CCP}(\mathrm{s})$ as compared to market participants' exposures to each other and to CCPs using weight $\omega$. This weight reflects that, despite a regulator's interest in controlling systemic risk from all sources, they may not necessarily treat a CCP's exposures and a market participant's exposures as equivalent. For example, a CCP's direct regulator or overseer may be

\footnotetext{
${ }^{4}$ Without considering exposures between CCPs, a domestic CCP linked to an offshore CCP, and a single global CCP would be identical in terms of "netting efficiency".

${ }^{5}$ In a bilateral market without CCPs, total system exposures would simply be the weighted sum of market participants' exposures to each other.
} 
particularly concerned with the crucial role that a CCP plays in maintaining continuously open financial markets. Therefore these regulators may assign a value to weight $\omega$ (i.e. a level of importance to the CCP's exposures to participants or to linked CCPs) that is at least if not greater than $1 .{ }^{6}$ Prudential regulators may conversely be more concerned about market participants' exposures to the CCP and assign a weight equal to or less than 1 to CCP exposures. Regulators may also consider the type of risk proofing associated with each kind of exposure. Typically, market participants (often dealers) are required to hold capital against their CCP exposures while CCPs require initial margin to offset their exposures to clearing members and/or other linked CCPs. Since capital is a survivor pays loss absorption mechanism while collateral remains defaulter pays, this could impact the relative weight assigned to CCP and participant exposures. We explore different values of $\omega$ later on to integrate these different views.

It should also be noted that more than one relative importance parameter $\omega$ could exist in a clearing system. For example, a regulator with direct oversight of a local CCP could view the local CCP's exposures as being more important than the exposures of a foreign CCP, giving rise to preference parameters $\omega_{D O M}$ and $\omega_{F O R}$. Alternatively, a regulator could weight each CCP's exposures to market participants differently from its exposures to linked CCPs, if for example these were risk managed in a different way. For simplicity, we introduce a uniform weight $\omega$ to all CCP exposures.

Finally, in our simple model we ignore collateralization of positions. The fundamental results do not change if we relax this assumption and allow collateralization to be comparable across exposures.

\section{$5 \quad$ Clearing models examined}

\subsection{A bilateral market}

We begin our analysis with a bilateral OTC derivatives market where there are $N$ participants who all trade in a single derivatives contract. This contract has no market value at origination but takes on value as the price of its underlying asset changes; creating the possibility of a replacement cost loss if a counterparty were to default. Such a setup would be equivalent to a contract that is frequently marked-to-market with an exchange of variation margin to reset its value to zero. For simplicity, we assume that each of the $N$ participants in the market trades with all other participants.

\footnotetext{
${ }^{6}$ Since a weight of 1 is applied to market participant exposures, a value of $\omega$ greater than 1 implies a greater importance placed on CCP exposures.
} 
We define $V_{i j}$ as the bilateral net exposure between market participants $i$ and $j$. This represents the current net market value of contracts outstanding between participants $i$ and $j$. For simplicity, $V_{i j}$ are independent and identically distributed random draws from a normal distribution $N\left(0, \sigma^{2}\right) . V_{i j}>0$ means that $i$ has an "in the money" position while $j$ is "out of the money" whereas $V_{i j}<0$ means that $j$ is "in the money" whereas $i$ is "out of the money". Each long position must have an equal and offsetting short position whereby $V_{j i}=-V_{i j}$.

To illustrate the bilateral market, we construct a matrix $V$ of net positions between participants; therefore $V$ represents a snapshot of bilateral exposures between market participants today. In a simple market with only four participants, $V$ is a $4 \mathrm{x} 4$ skew-symmetric matrix with zeros along the diagonal:

$$
V=\left[\begin{array}{cccc}
0 & V_{12} & V_{13} & V_{14} \\
V_{21} & 0 & V_{23} & V_{24} \\
V_{31} & V_{32} & 0 & V_{34} \\
V_{41} & V_{42} & V_{43} & 0
\end{array}\right] .
$$

We extend our analysis to include two countries, a domestic market (DOM) and a larger foreign market (FOR). Each country has a set of unique and non-overlapping market participants ${ }^{7}$. There are $N_{D O M}$ participants in the domestic country, and $N_{F O R}$ participants in the foreign country.

We number the participants in DOM from $i=1, \ldots, N_{D O M}$ and in FOR from $i=N_{D O M}+$ $1, \ldots, N_{D O M}+N_{F O R}$. Our matrix $V$ can now be divided into quadrants to identify trades within and across jurisdictions:

$$
V=\left[\begin{array}{cc}
\text { Within DOM } & \text { From DOM to FOR } \\
\text { From FOR to DOM } & \text { Within FOR }
\end{array}\right]
$$

Having outlined the bilateral market for OTC derivatives, we now introduce CCPs, central clearing, and the associated impacts of multilateral netting. As previously outlined, we will examine three central clearing models:

- a single global CCP

- a CCP in the domestic country that clears only within-country trades while the CCP in the foreign country clears the remainder

\footnotetext{
${ }^{7}$ The assumption of non-overlapping participants would apply, for example, if each financial institution traded products only through a single subsidiary to maximise netting opportunities.
} 
- linked domestic and foreign CCPs

\subsection{Different CCP configurations}

In our global CCP model (Figure 1a), the full set of $N_{D O M}$ domestic market participants and $N_{F O R}$ offshore market participants clear their trades through a single global CCP (GCCP). Through novation, the CCP replaces a participant's bilateral exposures from matrix $V$ with a single exposure to the CCP itself. Therefore, in a single CCP model participants are said to benefit from full multilateral netting amongst all participants in the market.

Our second clearing model involves two unlinked CCPs (Figure 1b). Domestic trades where both counterparties are domestic are cleared by the domestic CCP (CCP DOM), while trades between domestic and foreign counterparties are cleared by the foreign CCP (CCP FOR). In this model with two unlinked CCPs, participants cannot freely choose which CCP to clear at and this is instead determined by the location of their counterparty. In this way, CCP FOR represents a larger CCP that admits participants across jurisdictions and clears products for several markets. For trades where both counterparties are located in the foreign country, CCP FOR clears the trade. The matrix of bilateral exposures $V$ is now reduced to domestic participants' exposures to both CCP DOM and CCP FOR, while foreign participants are exposed only to CCP FOR.

Finally, we examine a model where the CCPs in the domestic and the foreign countries each serve their respective market participants and are joined by a link (Figure 1c). In situations where both counterparties to a trade are domestic, CCP DOM clears the trade. Similarly, where both counterparties to a trade are in the foreign country, CCP FOR clears the trade. For cross-country trades, CCP DOM clears the leg of the trade with the domestic market participant, CCP FOR clears the leg of the trade with the foreign participant and an inter-CCP contract arises. As we show in the next section, the exposure between CCP DOM and CCP FOR represents the aggregate net exposure of domestic participants to foreign participants, and vice versa. 


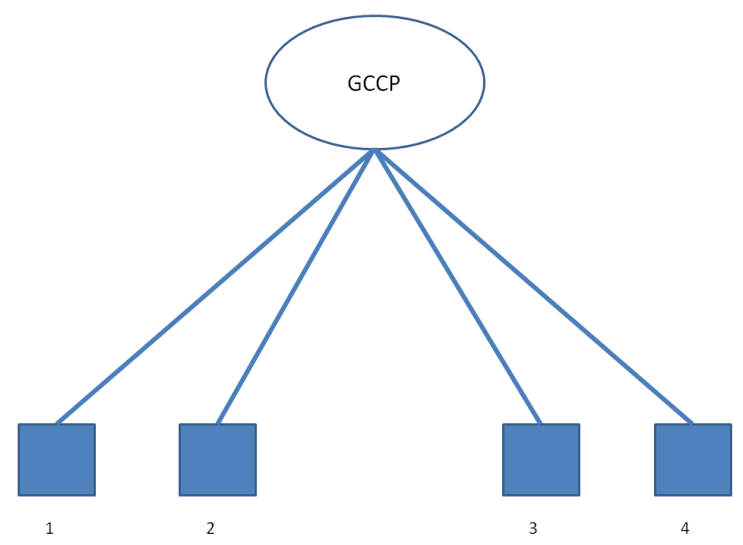

Figure 1a: Global CCP.

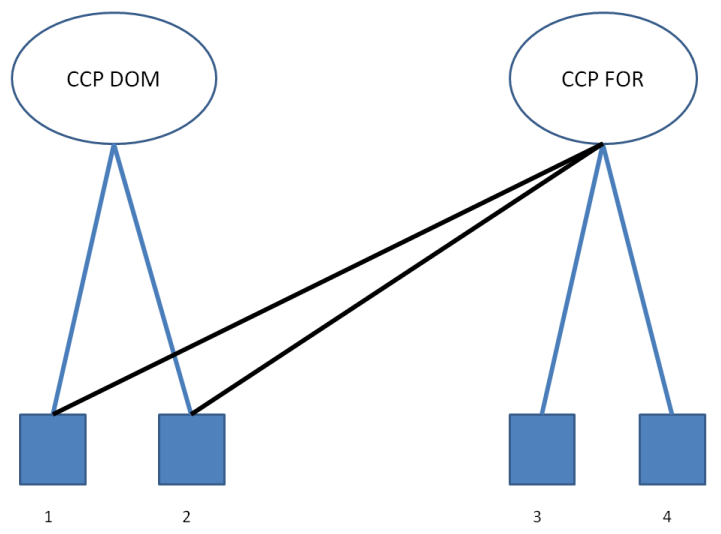

Figure 1b: Two unlinked CCPs.

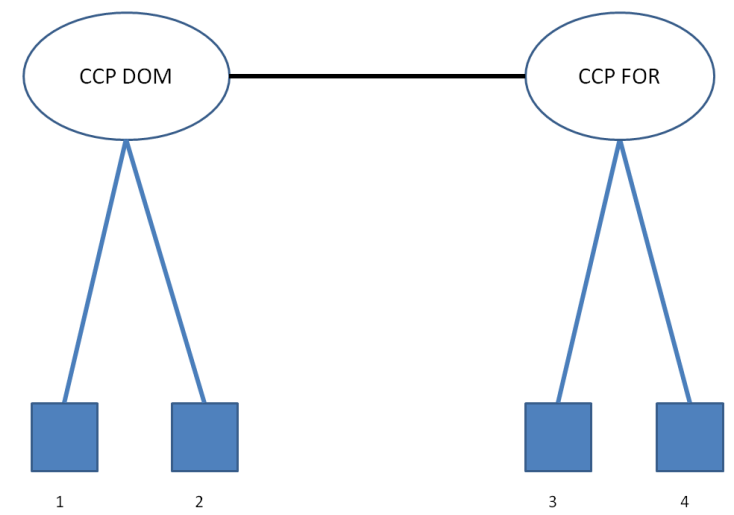

Figure 1c: Linked domestic and foreign CCPs. 
We assume no change to our matrix of positions $V$ between participants regardless of the clearing configuration examined. It is conceivable that market participants could change their trading behaviour based on the CCP setup, for example, by concentrating trades with domestic counterparties in an unlinked CCP world. However, the global nature of OTC derivatives markets suggests that some level of cross-border trading would always occur. To simplify the comparison between configurations, we adopt the same matrix of trades. A different trading behavior could be modelled using different distributions of positions.

\section{Total System Exposure under the Different Config- urations}

In the sections that follow we obtain analytical expressions of total system exposures for each configuration.

\subsection{A bilateral market}

We begin with a bilateral market that can be described by the matrix of net exposures $V$, where each participant trades with all others. We continue to assume that bilateral exposures $V_{i j}$ are independent and identically distributed random draws from a normal distribution $N\left(0, \sigma^{2}\right)$. The derivative contract traded has no value at time $t=0$.

For the purposes of netting efficiency and its impact on market participants' exposures, we consider only expected positive exposures at $t=1$, denoted:

$$
E\left[\max \left(V_{i j}, 0\right)\right]
$$

In other words, only a market participant's derivatives positions that have positive value are a source of exposure if their counterparty were to default. We can then define the total exposure of participant $i$ in a bilateral market as the sum of its exposures to all other participants. $^{8}$

\footnotetext{
${ }^{8}$ If $X_{1}, \ldots, X_{N}$ are independent and identically distributed random variables with distribution $N\left(0, \sigma^{2}\right)$, then

$$
E\left[\max \left(X_{1}+\ldots+X_{N}, 0\right)\right]=E[\max (s, 0)]
$$

where $s=X_{1}+\ldots X_{N} \sim N\left(0, N \sigma^{2}\right)$. Therefore

$$
E[\max (s, 0)]=\frac{1}{\sqrt{2 \pi N} \sigma} \frac{1}{2}\left[\left(-2 N \sigma^{2}\right) e^{-\frac{s^{2}}{2 N \sigma^{2}}}\right]_{0}^{+\infty}=\sqrt{\frac{N}{2 \pi}} \sigma .
$$
}




$$
\gamma_{i}^{O T C}=E\left[\sum_{i \neq j} \max \left(V_{i j}, 0\right)\right]=(N-1) E\left[\max \left(V_{i j}, 0\right)\right]=(N-1) \sqrt{\frac{1}{2 \pi}} \sigma .
$$

As shown by equation 1, a market participant's exposures in a bilateral market are a function of only two variables: the number of participants in the market $(N)$ and the volatility of the derivative contract $(\sigma) .{ }^{9}$ From this, we define total system exposure in a bilateral market as the sum of each individual participant's bilateral exposures.

$$
\gamma_{\text {System }}^{\text {OTC }}=\sum_{i=1, . ., N} \gamma_{i}^{\text {OTC }}=N(N-1) \sqrt{\frac{1}{2 \pi}} \sigma
$$

Note that since there is no CCP, total system exposure is simply equal to the sum of each participant's exposure to all other participants.

\subsection{A single global CCP}

Assuming that the values of $V_{i j}$ are independent and identically distributed random draws from a normal distribution, Duffie and Zhu (2011) show that, in a market with a single CCP and $N$ participants, the expected exposure of each market participant $i$ can be represented by equation 3 below.

$$
\gamma_{i, G C C P}^{\text {Global }}=E\left[\max \left(\sum_{j \neq i} V_{i j}, 0\right)\right]=\sqrt{\frac{N-1}{2 \pi}} \sigma
$$

Equation 3 is the result of multilateral netting of exposures across all participants in the derivatives market as trades are novated to the CCP and it becomes counterparty to each trade. Importantly, under this model and other models involving one or more CCPs, we examine the exposure of market participant $i$ to the failure of the CCP as counterparty only. We do not consider another source of exposure for clearing members - the mutualisation of another market participant's default via default fund contributions or other loss-sharing mechanisms. Because of different possible approaches to default mutualisation across CCPs,

\footnotetext{
${ }^{9}$ Note that we are assuming constant volatility in the two countries. Although this assumption does not need to be true (one country could have different economic conditions that affect volatility), a different volatility introduces a scale effect in the expected exposure formula that simply rescales our results. More precisely, if domestic and foreign countries have volatilities $\sigma_{D O M}=h \sigma_{F O R}$ then the expected exposure of the domestic country can be expressed in terms of the volatility of the foreign country by rescaling the number of clearing members:

$$
\sqrt{\frac{N_{D O M}}{2 \pi}} \sigma_{D O M}=\sqrt{\frac{h^{2} N_{D O M}}{2 \pi}} \sigma_{F O R} .
$$
}


the choice to focus on default exposures is a simplifying assumption that could alter the magnitude of losses in our study but should not alter the direction of our results. We also assume that $\gamma_{i, G C C P}^{\text {Global }}$ represents an exposure that has not been extinguished by the CCP through the payment of variation margin to the market participant. ${ }^{10}$

After introducing a global CCP, a market participant's exposure grows with the square root of $N$ as seen in equation 3. We compare this to a bilateral market without a CCP, where a participant's exposures grow linearly with $N$. This expression illustrates how there are important gains in multilateral netting when OTC trades are novated to a CCP.

Note that so far we have only considered the market participants' exposures to the CCPs, we next move on to consider the expected exposures taken on by the CCP itself.

When trades are novated to the CCP, multilateral netting of bilateral positions takes place; participant $i$ has exposure $\sum_{j \neq i} V_{i j}$ to the CCP and the CCP has exposure $\sum_{j \neq i} V_{j i}$ to participant $i$. The expected positive values of these two exposures are the same. Therefore, the CCP's total expected positive exposure to all market participants is equal to the aggregate expected positive exposure of market participants to the CCP scaled by the factor $\omega$, which represents the relative importance placed on CCP exposures as compared to market participants' exposures.

$$
\gamma_{G C C P}^{G l o b a l}=\omega N\left(\gamma_{i, G C C P}^{G l o b a l}\right)=\omega N \sqrt{\frac{N-1}{2 \pi}} \sigma
$$

where $\omega \geq 0$.

In the case where $\omega=1$, risks to the CCP, as measured by its exposure to members, are of equal importance to regulators as risks to market participants.

The total system exposure for both market participants and the CCP is then simply:

$$
\gamma_{\text {System }}^{\text {Global }}=N\left(\gamma_{i, G C C P}^{\text {Global }}\right)+\gamma_{G C C P}^{\text {Global }}=(1+\omega) N \sqrt{\frac{N-1}{2 \pi}} \sigma \quad \text { where } \quad N=N_{D O M}+N_{F O R}
$$

\subsection{A domestic CCP and an unlinked foreign CCP}

In the unlinked CCP model, domestic participants have two exposures: exposures to CCP DOM for their trades with domestic counterparties and exposures to CCP FOR for their

\footnotetext{
${ }^{10}$ The number of clearing members in a CCP could affect a participant's exposures to a CCP due to loss mutualisation. For example, if the number of participants is small the default of a member in the most extreme market conditions may imply large contributions by survivors to cover the losses not covered by the initial margins and default fund contributions of the defaulting member.
} 
trades with foreign counterparties. Participants in the foreign country have exposures only to CCP FOR.

Given this, a domestic market participant's exposure is the expected sum of its exposure to each CCP. Using equation 3 for the exposure to a single CCP, we obtain:

$$
\begin{gathered}
\gamma_{i, C C P \text { DOM }}^{\text {unlinked }}=E\left[\max \left(\sum_{j=1, . ., N_{D O M}} V_{i j}, 0\right)\right]+E\left[\max \left(\sum_{k=\left(N_{D O M}+1\right), . ., N_{F O R}} V_{i j}, 0\right)\right] \\
\text { for } i=1, \ldots, N_{D O M},
\end{gathered}
$$

which simplifies to,

$$
\gamma_{i, C C P D O M}^{\text {unlinked }}=\sqrt{\frac{N_{D O M}-1}{2 \pi}} \sigma+\sqrt{\frac{N_{F O R}}{2 \pi}} \sigma \quad \text { for } i=1, \ldots, N_{D O M} .
$$

Similarly, the exposure of a participant in the foreign country is given by its expected exposure to CCP FOR:

$$
\begin{aligned}
\gamma_{i, C C P \text { FOR }}^{\text {unlinked }} & =E\left[\max \left(\sum_{j=1, \ldots, N_{F O R}, j \neq i} V_{i j}, 0\right)\right]=\sqrt{\frac{N_{D O M}+N_{F O R}-1}{2 \pi}} \sigma \\
\text { for } i & =N_{D O M}+1, \ldots, N_{D O M}+N_{F O R} .
\end{aligned}
$$

Hence, the total exposure of all market participants is the sum of the individual exposures of participants in both the domestic and foreign countries:

$$
\begin{aligned}
\gamma_{\text {participants }}^{\text {unlinked }} & =\sum_{i=1, . ., N_{D O M},} \gamma_{i, C C P D O M}^{\text {unlinked }}+\sum_{i=N_{D O M}+1, . ., N_{F O R}} \gamma_{i, C C P F O R}^{\text {unlinked }}, \\
& =N_{D O M} \sqrt{\frac{N_{D O M}-1}{2 \pi}} \sigma+N_{D O M} \sqrt{\frac{N_{F O R}}{2 \pi}} \sigma+N_{F O R} \sqrt{\frac{N_{D O M}+N_{F O R}-1}{2 \pi} \sigma .}
\end{aligned}
$$

In addition, the total expected exposure of each CCP to its market participants is going to be equal to the aggregate expected exposure of market participants to the CCP scaled by the factor $\omega$.

Therefore, the total system exposure for this model, accounting for the exposures of all market participants and the exposures of the CCPs themselves is equal to $(1+\omega)$ times the total exposures of all participants as previously demonstrated: 


$$
\gamma_{\text {System }}^{\text {unlinked }}=(1+\omega)\left(N_{D O M} \sqrt{\frac{N_{D O M}-1}{2 \pi}} \sigma+N_{D O M} \sqrt{\frac{N_{F O R}}{2 \pi}} \sigma+N_{F O R} \sqrt{\frac{N_{D O M}+N_{F O R}-1}{2 \pi} \sigma}\right) .
$$

\subsection{Clearing link between the two CCPs}

We now assume that there are two CCPs that share a clearing link, one located in the domestic country and one in the foreign country. In this configuration, CCPs remain directly exposed to their own local market participants and also bear an inter-CCP exposure that is equivalent to the net trades that participants have across regions.

As shown previously, the link allows participants in each country to multilaterally net their positions across all counterparties while being members of only the CCP in their jurisdiction and achieve an equivalent level of netting as the global CCP model. Given this, a participant's expected exposure in each region would be expressed similarly to equation 3 :

$$
\begin{gathered}
\gamma_{i, C C P D O M}^{\text {linked }}=\sqrt{\frac{N_{D O M}+N_{F O R}-1}{2 \pi}} \sigma \quad \text { for } i=1, \ldots, N_{D O M}, \\
\gamma_{i, C C P F O R}^{\text {linked }}=\sqrt{\frac{N_{D O M}+N_{F O R}-1}{2 \pi}} \sigma \quad \text { for } i=N_{D O M}+1, \ldots, N_{D O M}+N_{F O R} .
\end{gathered}
$$

With the total exposure of all participants being equal to the sum of individual participant's exposures:

$$
\gamma_{\text {participants }}^{\text {linked }}=\left(N_{D O M}+N_{F O R}\right) \sqrt{\frac{N_{D O M}+N_{F O R}-1}{2 \pi}} \sigma .
$$

In order to arrive at a measure of total system exposure, we once again sum CCP exposures and participant exposures. Each CCP's exposure is given by the sum of its exposure to market participants and its exposure to the other CCP across the link. Again, we use a weight $\omega$ to take into account the importance of CCP exposures. Specifically, for CCP DOM we have:

$$
\gamma_{C C P D O M}^{\text {linked }}=\omega N_{D O M} E\left[\max \left(\sum_{j=1, \ldots, N_{D O M}, j \neq i} V_{i j}, 0\right)\right]+\omega E\left[\max \left(\sum_{i=1, \ldots, N_{D O M}} \sum_{j=1, \ldots, N_{F O R}} V_{i j}, 0\right)\right] .
$$


This simplifies to:

$$
\gamma_{C C P D O M}^{\text {linked }}=\omega N_{D O M} \sqrt{\frac{N_{D O M}+N_{F O R}-1}{2 \pi}} \sigma+\omega \sqrt{\frac{N_{D O M} N_{F O R}}{2 \pi}} \sigma .
$$

Similarly for CCP FOR we have:

$$
\gamma_{C C P F O R}^{\text {linked }}=\omega N_{F O R} \sqrt{\frac{N_{D O M}+N_{F O R}-1}{2 \pi}} \sigma+\omega \sqrt{\frac{N_{D O M} N_{F O R}}{2 \pi}} \sigma .
$$

Finally, the total system exposure is given by the sum of CCP exposures and market participants' exposures from equations 12, 13 and 14:

$$
\gamma_{\text {System }}^{\text {linked }}=(1+\omega)\left(N_{D O M}+N_{F O R}\right) \sqrt{\frac{N_{D O M}+N_{F O R}-1}{2 \pi}} \sigma+2 \omega \sqrt{\frac{N_{D O M} N_{F O R}}{2 \pi}} \sigma .
$$

\section{Comparing clearing configurations in terms of total system exposures}

By comparing each clearing configuration in terms of total system exposures, we reach the central result for our paper.

The global CCP case is the benchmark because it yields the lowest level of total system exposures. This reflects that market participants can net their exposures across the full set of market participants at a global CCP. Whereas this is also a feature of the linked CCP model, linking CCPs gives rise to inter-CCP exposures.

The other two clearing configurations, the unlinked and linked CCPs, cannot be uniquely ranked as the level of total system exposure depends on the relative number of market participants in each country. The following result presents the intuition for these two latter configurations (see Appendix A for proof):

Result 1 If $N_{D O M}$ is relatively low with respect to $N_{F O R}$ then total system exposure is greater in the linked rather than the unlinked scenario, whereas when $N_{D O M}$ is relatively high with respect to $N_{F O R}$, then total system exposure is greater in the unlinked scenario.

A more intuitive explanation is given and expanded upon in the following sections. A link between two CCPs introduces inter-CCP exposures while removing domestic clearing 
members' direct exposures to a foreign CCP. Assuming they trade with foreign country participants, domestic participants always achieve a greater level of netting under the linked clearing model because they are able to multilaterally net positions across all their counterparties - which in turn reduces their exposures.

On the other hand, the domestic CCP always sees increased exposures when a link is introduced. Without the link, CCP DOM is exposed only to the default of each domestic market participant and these exposures represent the participant's net position with all other domestic participants. When the link is introduced, CCP DOM remains exposed to each domestic participant, however, their positions with the CCP now reflect net trades with both domestic and foreign participants. In addition, the domestic CCP gains exposure to the linked foreign CCP.

When the number of domestic participants is small, the netting gains achieved by domestic markets participants from the link do not compensate for the increase in exposures to the domestic CCP. Therefore, the unlinked case can be better than the linked configuration in terms of reducing total system exposures.

Below we present a graphical analysis of the level and breakdown of total system exposures in the different clearing configurations. For our analysis, we set the volatility of the derivative contract constant at 1 and the number of market participants in the foreign country at 20; we vary the number of market participants in the domestic country and the relative importance of CCP exposures, $\omega$.

\subsection{Total system exposures when CCP and market participant exposures are equally weighted $(\omega=1)$}

Figures 2 and 3 show average total system exposures in each clearing model as the number of domestic participants increases, holding the number of foreign participants constant at 20. Since each additional domestic participant trades equally with all other market participants, total system exposure increases linearly with the number of domestic participants in each clearing model. The level and slope of exposures in the bilateral OTC case is the greatest since there is no multilateral netting. A single global CCP maximizes netting without creating inter-CCP exposures so it results in the lowest average total system exposure regardless of the number of domestic participants. Comparing the other two models illustrates our earlier result that whether the linked or unlinked configuration is better from a total system perspective depends on the number of domestic participants relative to the number of foreign participants. 
For a small relative number of domestic participants, the unlinked case results in a lower average total system exposure, while for a larger relative number of domestic participants the opposite is true. For the values specified, the two set-ups are equivalent when the ratio of domestic participants to foreign participants is about $1 / 3$.

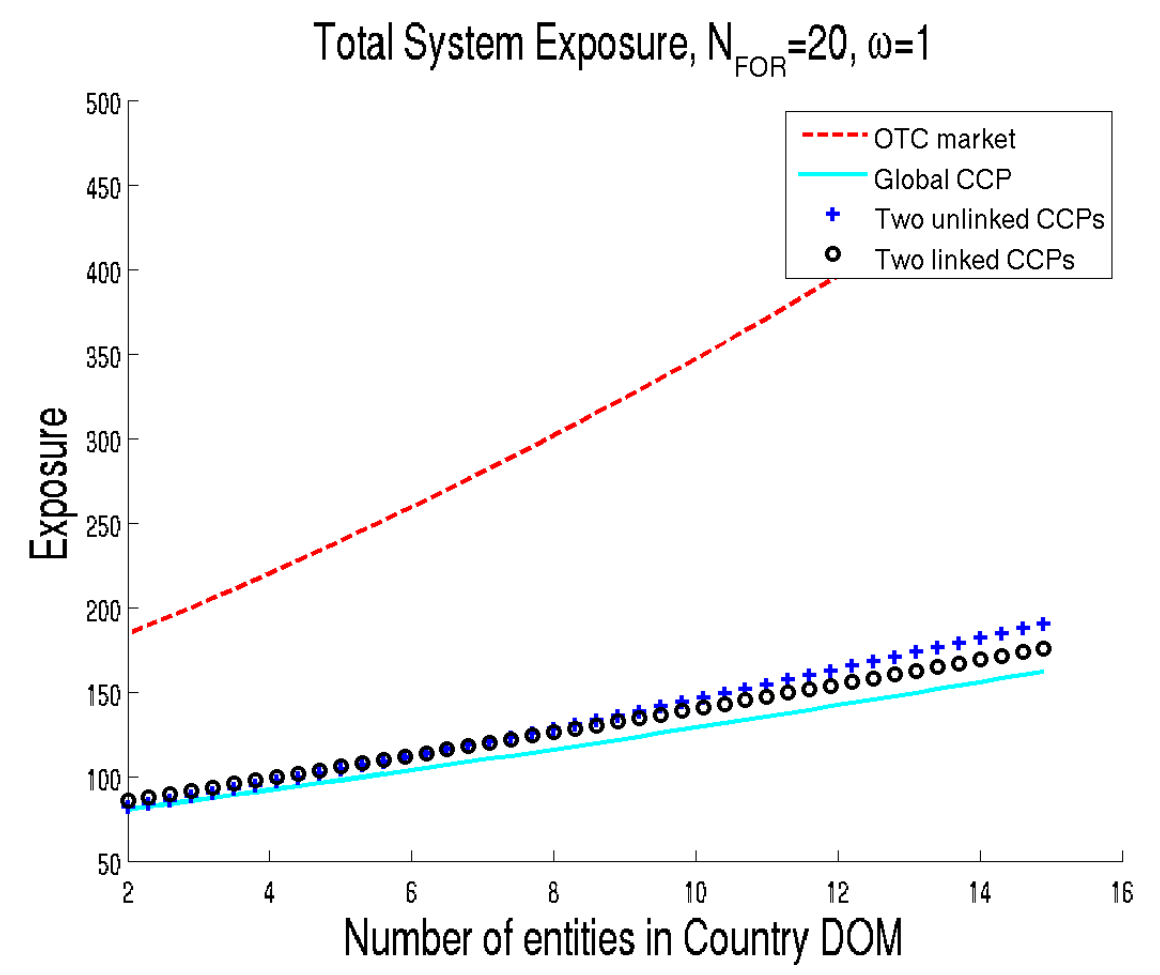

Figure 2: Average Total System Expected Exposures (including OTC bilateral trading) 


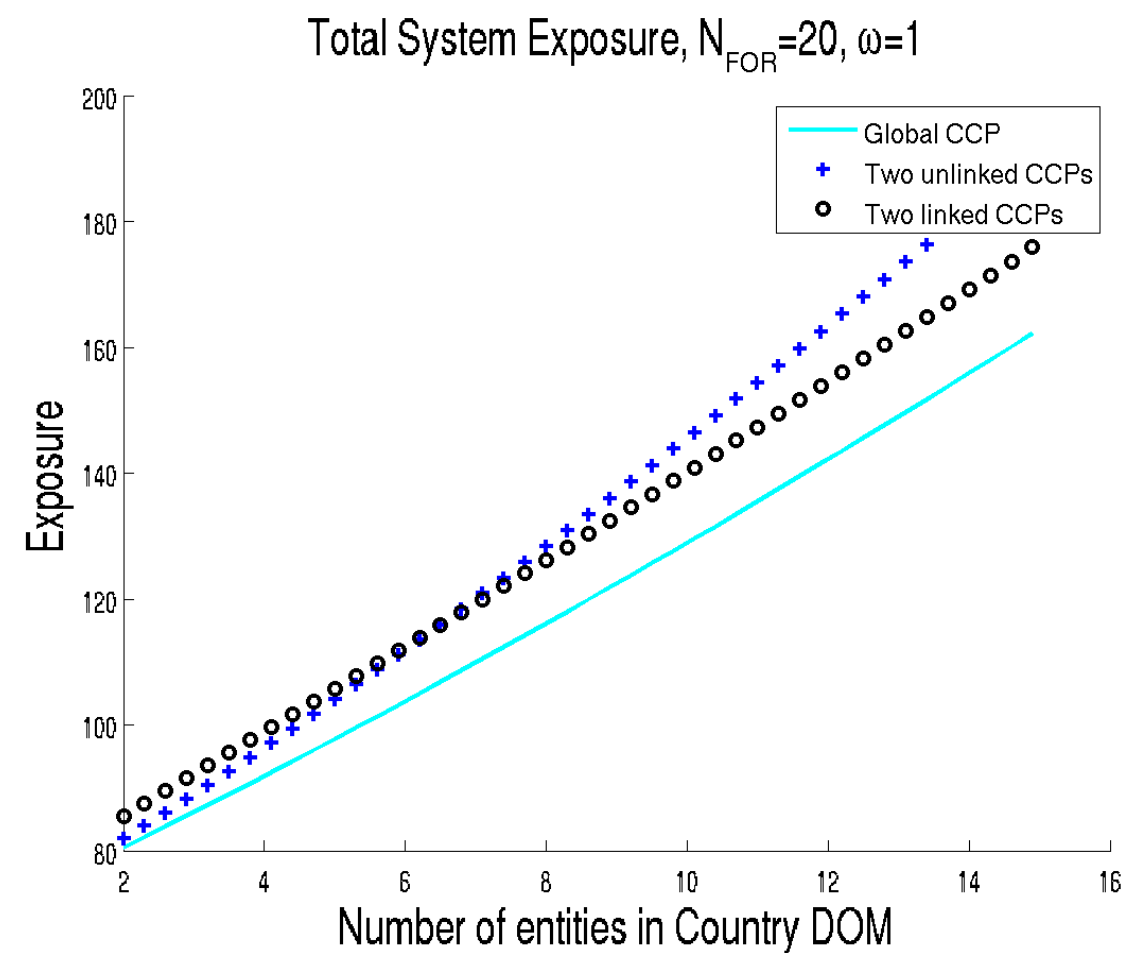

Figure 3: Average Total System Expected Exposures

In order to better illustrate this result, in figure 4 below we show the exposures for CCP DOM and CCP FOR under the linked and unlinked clearing models. The net effect from introducing an inter-CCP link combines three shifts in exposures: 1) the reduced exposures taken on directly by CCP FOR, 2) the reduction in domestic participants' exposures through greater netting and 3) the increase in exposures taken on by CCP DOM. 


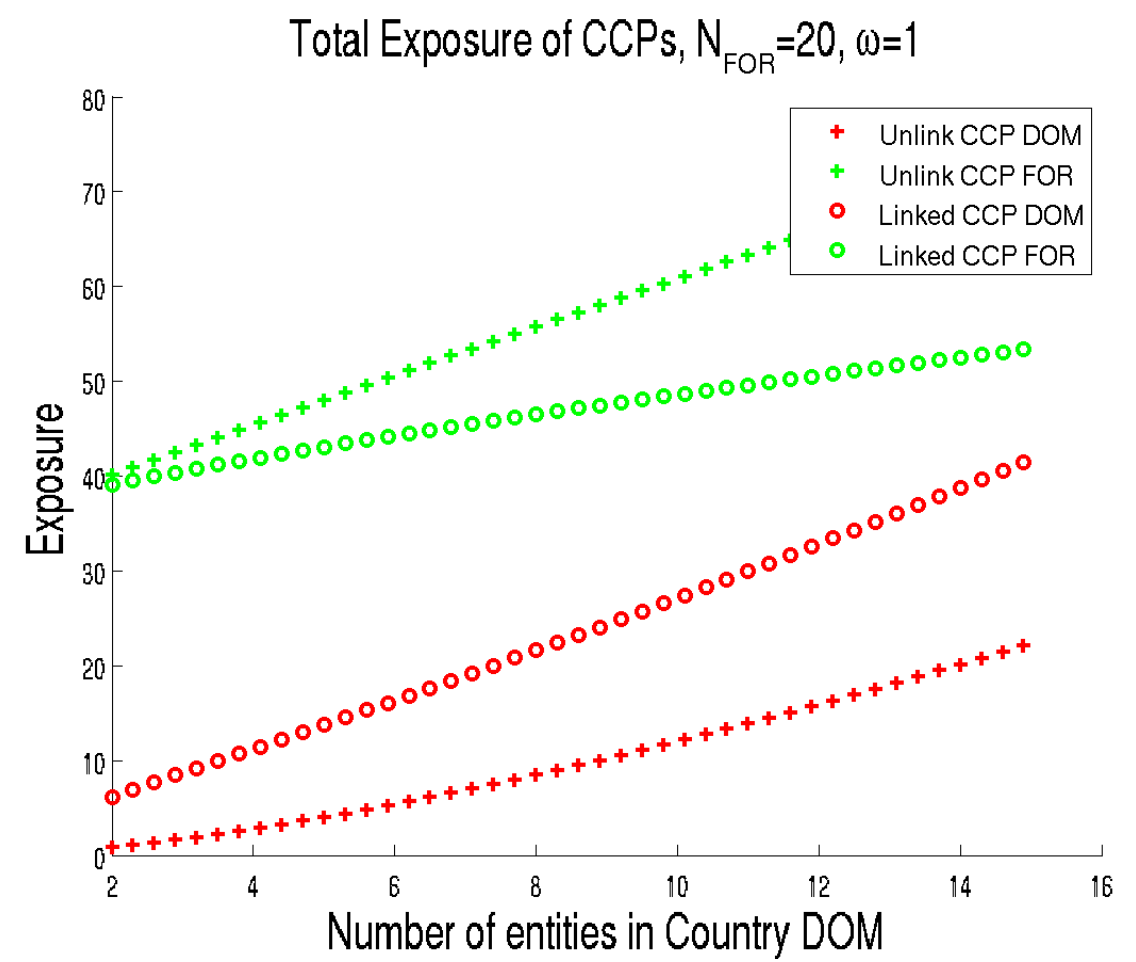

Figure 4: Average Expected Exposures for CCP DOM and CCP FOR

The results illustrate that CCP FOR's exposures are always lower under a linked than an unlinked scenario and that there is a large difference in the rate of change (slope) of expected exposures at an unlinked and a linked CCP FOR as domestic participants are added. In the unlinked case, a new domestic participant becomes a clearing member of both CCPs. As a result, the unlinked CCP FOR is directly exposed to the default of this new domestic participant. In addition, CCP FOR bears a greater default exposure to foreign participants since their net positions have grown due to trading with the new domestic dealer.

In the linked case, CCP FOR is not directly exposed to the default of an additional domestic participant. CCP FOR continues to bear an exposure to foreign participants' net exposures to the new domestic participant (similar to the unlinked case). However, under a link CCP FOR no longer has a direct exposure to the new domestic participant for its trading with foreign participants. CCP FOR instead bears additional exposure to the linked CCP because CCP DOM guarantees the trades of the new domestic participant with participants in the foreign country. CCP FOR's additional exposure to CCP DOM is a single net position of all domestic participants' trades with foreign participants. As compared to CCP FOR taking on a direct exposure to a new domestic participant in the unlinked case, CCP FOR's marginal exposure incurred through the link with CCP DOM is less due to multilateral 
netting between participants for linked exposures.

CCP DOM on the other hand, always sees increased exposures when a link is introduced. Without the link, CCP DOM is exposed only to the default of each domestic participant and these exposures represent the participant's net position with all other domestic participants. When the link is introduced, CCP DOM remains exposed to each domestic participant, however, their positions with the CCP now reflect net trades with both domestic and foreign participants. In addition, CCP DOM bears an exposure to CCP FOR that is the net exposure of foreign participants' trading with domestic participants.

Given this divergence in incentives between the domestic and foreign CCPs, it is questionable whether a link would ever arise organically between two such CCPs. This may or may not be optimal from a total system perspective. Total system exposures may be greater under a linked than under an unlinked model when the number of domestic market participants is relatively small. Under these circumstances, CCP FOR benefits very little from shedding its direct exposures to domestic participants in favour of a linked exposure to CCP DOM because there are so few of them. Similarly, domestic participants already trade mostly with foreign participants (since foreign participants dominate the market) and achieve the majority of their netting gains from participation in CCP FOR. Allowing domestic participants to net across both domestic and foreign participants thus provides only a small benefit in terms of overall exposures. However, CCP DOM sees a large increase in expected exposures from its link with CCP FOR due to the large number of foreign participants and their net trading activity with domestic participants - which is the source of the linked exposure. In other words, if the foreign CCP were to default, CCP DOM would now be responsible for fulfilling the obligations of a large number of trades that foreign participants had with its set of domestic market participants.

\subsection{Total system exposures when CCP exposures and market par- ticipant exposures are weighted differently $(\omega \neq 1)$}

We now repeat our analysis using different values of $\omega \cdot{ }^{11}$ Figure 5 below illustrates how the threshold numbers of domestic participants, at which a link is preferred (i.e. the point at which unlinked and linked exposures cross), varies according to the level of importance assigned to CCP exposures relative to market participant exposures. The baseline case of $\omega=1$ is shown on the graph.

As can be seen, when a low weight is applied to CCP exposures (i.e. regulators have a relative preference for CCP exposures) the threshold number of domestic participants at

\footnotetext{
${ }^{11}$ Appendix 2 shows a more detailed graphical analysis for the case $\omega=0.5$.
} 
which the linked case leads to lower total system exposures than the unlinked CCP case is low. ${ }^{12}$ For low levels of $\omega$ the linked configuration requires only a small number of domestic market participants, each benefiting from multilateral netting, to offset the creation of low weighted inter-CCP exposures. In the extreme case where $\omega=0$, the linked case would be as efficient and lead to the same level of total system exposures as the global CCP case for any number of domestic participants. This result is intuitive and would occur because we ignore the CCPs' exposures while market participants achieve full multilateral netting in both cases and attain the same low level of exposures in the market. With no weight applied to the CCPs' exposures, the unlinked case would always be worse in terms of exposures because of lower netting opportunities for market participants due to fractured clearing.

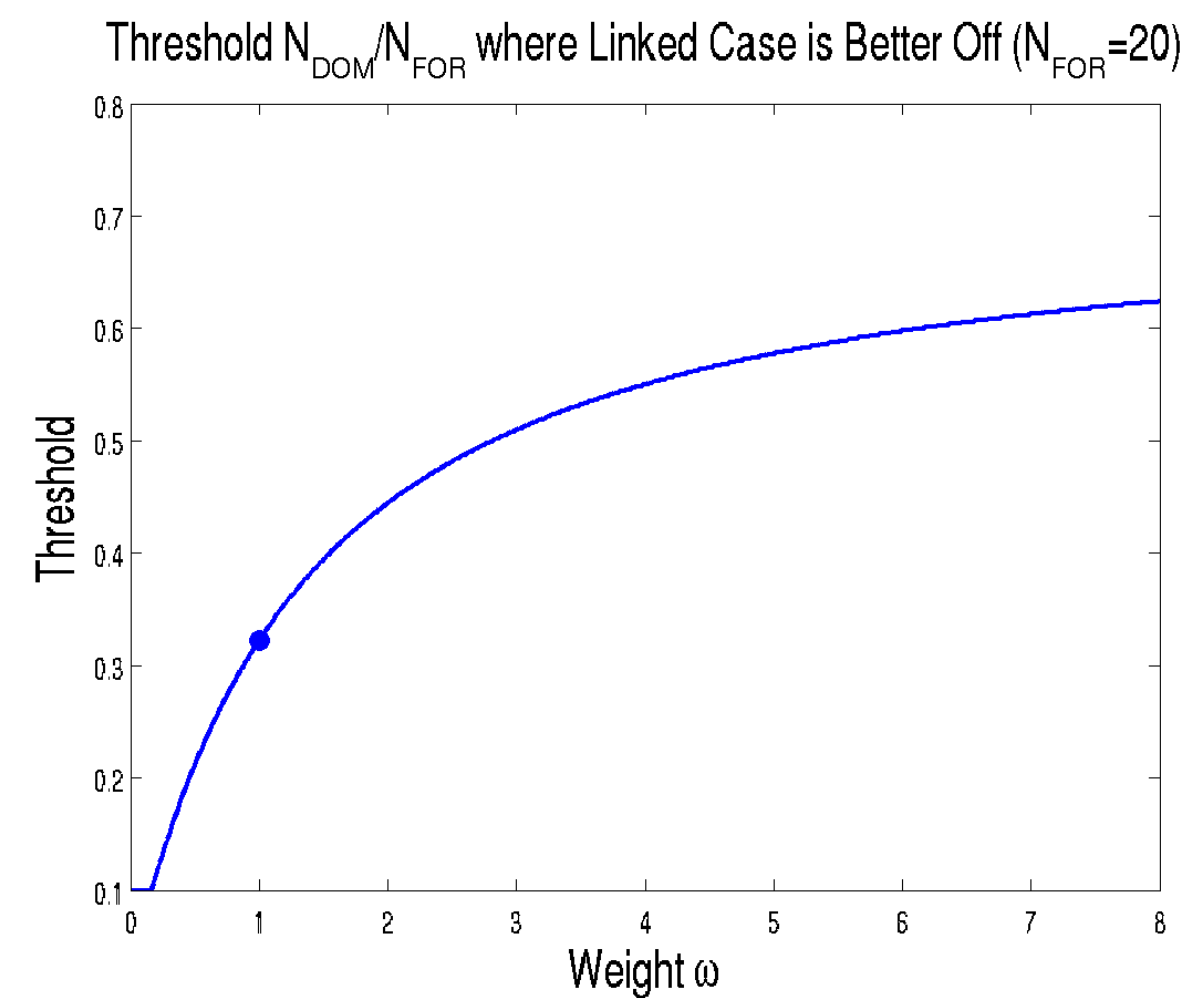

Figure 5: Threshold domestic CCP membership where total system exposures are equal under linked and unlinked cases

As the relative weight applied to CCP exposures increases, so does the threshold number of domestic participants at which the linked case is preferred from a total system perspective. The "bar is raised," in other words, for links between CCPs to be the preferred configuration. With a higher weight applied to inter-CCP exposures, a larger number of domestic market

\footnotetext{
${ }^{12}$ Note that the graph does not reach a threshold equal to zero because we do not consider a number of domestic participants lower than two.
} 
participants, each benefiting from multilateral netting, is required to offset the increased inter-CCP exposures. Figure 5 shows how this optimum threshold increases at a decreasing rate as we increase the weight $\omega$. When $\omega$ is low, a small increase in the importance placed on CCP exposures results in a large increase in the number of domestic members required to justify a link. When a high weight is already put on CCP exposures, however, the increase required in the number of domestic participants is marginal.

\section{Conclusion}

This paper provides a framework to examine the exposure trade-off that exists when two CCPs are linked, while incorporating regulatory preferences into the determination of the most efficient clearing configuration. To do so, we use the concept of total system exposure, which takes both market participant and CCP exposures into account. Our measure of total system exposures also incorporates a policy parameter $\omega$, which weights CCPs' exposures as compared to market participants' exposures. With this weight, we incorporate into our framework regulatory preferences for a given form of exposures in the market over another.

We first consider a world in which market participant exposures and CCP exposures are viewed as equal. A single global CCP results in the lowest total system exposure as it allows for multilateral netting across all participants while avoiding the creation of inter-CCP exposures via links. The linked scenario generally provides the second lowest level of total system exposure except when the number of participants at the local CCP is small relative to the number of participants at the global CCP.

Even though a link between a domestic CCP and a larger offshore CCP creates interCCP exposures, netting benefits incurred by market participants in the domestic market can outweigh these exposures. This result holds in a world where the number of market participants directly accessing the domestic CCP is above some minimum threshold. Yet, the decision to link CCPs may not be taken purely from a global systemic risk perspective and it is important to understand regulatory preferences as well.

We show how the impetus to link a domestic CCP to a larger foreign CCP increases as the importance (quantified by the parameter $\omega$ ) that is uniformly assigned by regulators to all CCP exposures decreases relative to the importance assigned to market participants' exposures. The domestic CCP always takes on larger default exposures under a linked rather than unlinked model due to its large exposure to a linked CCP. The domestic CCP's exposure to the linked CCP would therefore have to be weighted lower than its participants' exposures to CCPs in order to justify a link from the perspective of a domestic CCP. In this case, a 
linked configuration would be preferred by the domestic market since it provides the same degree of netting to domestic market participants as a global CCP and creates the largest drop in their default exposures. When less importance is placed on CCP exposures, the unlinked CCP case is only more efficient from a total system exposure perspective when the number of domestic participants is very small.

A lower regulatory weight on a domestic CCP's exposures as compared to domestic market participants' exposures could reflect that a regulator believes its oversight abilities reduce the risks taken on by the CCP. In a more realistic scenario, where market participants also bear the cost of collateralizing their exposures to CCPs, market forces would also support a link since market participants in the domestic market would achieve greater netting and post less collateral.

Finally, the preferences of the individual CCPs should also be taken into consideration. The foreign CCP should prefer exposures through a linked arrangement since the probability of default of a linked domestic CCP is lower than that of any market participant. However, with domestic market participants as members of the foreign CCP, it is able to extract clearing fees or other profits from these members; if it entered into a link with the domestic $\mathrm{CCP}$ as equal partners, it would be unlikely to receive this additional revenue. If a domestic CCP were to base its decision to link on exposures alone, it may require additional incentives to do so, since it always faces higher exposures under a linked set-up. Such incentives could include, for example, moral suasion applied by regulatory authorities or higher clearing fees than normally charged by equivalent infrastructure. 


\section{References}

Acharya, V. and A. Bisin (2011). Centralized versus over-the-counter markets. Working paper, New York University.

CGFS (2011). The macrofinancial implications of alternative configurations for access to central counterparties in otc derivatives markets. Technical Report 46, Bank for International Settlements.

Chande, N., J. Dion, D. McVanel, and J. Slive (2012). The Canadian Approach to Central Clearing for Over-the-Counter Derivatives. Bank of Canada Financial System Review.

Chande, N., N. Labelle, and E. Tuer (2010). Central Counterparties and Systemic Risk. Bank of Canada Financial System Review.

Duffie, D. and H. Zhu (2011). Does a central clearing counterparty reduce counterparty risk? Review of Asset Pricing Studies 1(1), 74-95.

Jackson, J. and M. Manning (2007). Comparing the pre-settlement risk implications of alternative clearing arrangements. Working paper, Bank of England.

Koeppl, T. and C. Monnet (2010). Emergence and future of central counterparties. Working paper, Queens University.

Mägerle, J. and T. Nellen (2011). Interoperability between central counterparties. Working Papers, Swiss National Bank.

Renault, F. (2010). Concentration risk and the optimal number of central counterparties for a single asset. Banque de France Financial Stability Review (14), 169-176.

Slive, J., C. Wilkins, and J. Witmer (2011). Access to central clearing services for over-thecounter derivatives. Bank of Canada Financial System Review. 


\section{Appendices}

\section{Appendix A Proof of Result 1}

Subtracting equation 9 from 15 gives an expression for the difference in total system exposures between the linked and unlinked clearing configurations:

$$
\begin{aligned}
\gamma_{\text {System }}^{\text {linked }}-\gamma_{\text {System }}^{\text {unlinked }} & \left.=\left((1+\omega) N_{D O M} \sqrt{\frac{N_{D O M}+N_{F O R}-1}{2 \pi}} \sigma-(1+\omega) N_{D O M} \sqrt{\frac{N_{D O M}-1}{2 \pi}} \sigma\right)\right) \\
& +\left(2 \omega \sqrt{\frac{N_{D O M} N_{F O R}}{2 \pi}} \sigma-(1+\omega) N_{D O M} \sqrt{\frac{N_{F O R}}{2 \pi} \sigma}\right) .
\end{aligned}
$$

By using the ratio $k=\frac{N_{F O R}}{N_{D O M}}$ between the sizes of the countries, this expression can be rewritten as follows:

$$
\begin{gathered}
\gamma_{\text {System }}^{\text {linked }}-\gamma_{\text {System }}^{\text {unlinked }}= \\
N_{D O M} \sqrt{\frac{\sigma^{2}}{2 \pi}}((1+\omega) A+2 \omega \sqrt{k}), \\
\text { with } \\
A=\sqrt{N_{D O M}(1+k)-1}-\sqrt{N_{D O M}-1}-\sqrt{k N_{D O M}}
\end{gathered}
$$

We analyze first the case where $N_{F O R} \gg N_{D O M}$. In that case $k \rightarrow+\infty$. It is easy to check that $\sqrt{N_{D O M}(1+k)-1}-\sqrt{k N_{D O M}} \rightarrow 0$. Therefore, the term $A$ is negative and finite (as long as $N_{D O M}>1$ ). On the other side, $2 \omega \sqrt{k} \rightarrow+\infty$. Therefore, for any value of $N_{D O M}$ equal or greater than $2, \gamma_{\text {System }}^{\text {linked }}-\gamma_{\text {System }}^{\text {unlinked }} \rightarrow+\infty$.

Now we analyze the case where $N_{F O R} \ll N_{D O M}$. In that case $k \rightarrow 0$ and $2 \omega \sqrt{k} \rightarrow 0$. By concavity of the square root function, the term $A$ is always negative. Also, $\sqrt{N_{D O M}(1+k)-1}-$ $\sqrt{N_{D O M}-1} \rightarrow 0$. But since $N_{F O R}>1$ by definition, then $A \rightarrow-\sqrt{N_{F O R}}$ which is finite and negative. Therefore, $\gamma_{\text {System }}^{\text {linked }}-\gamma_{\text {System }}^{\text {unlinked }}$ converges to a negative and finite number. This ends the proof of Result 1. 


\section{Appendix B Total System Exposures when $\omega=0.5$}

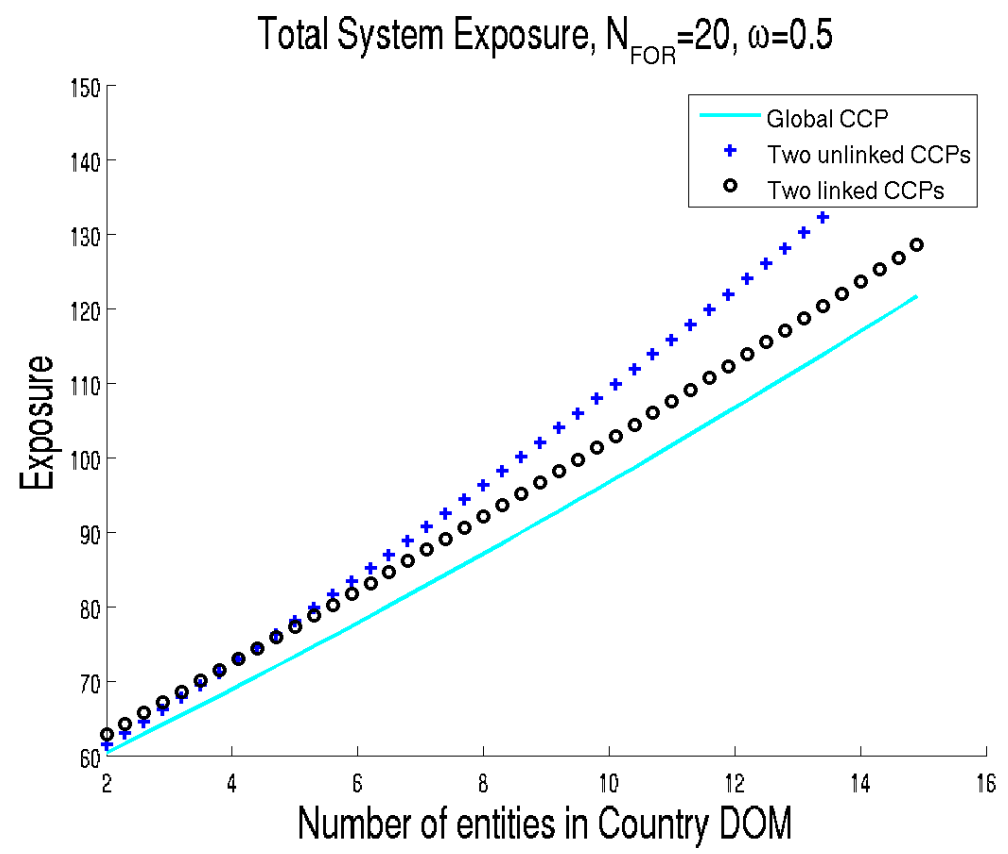

Figure 6: Average Total System Expected Exposures

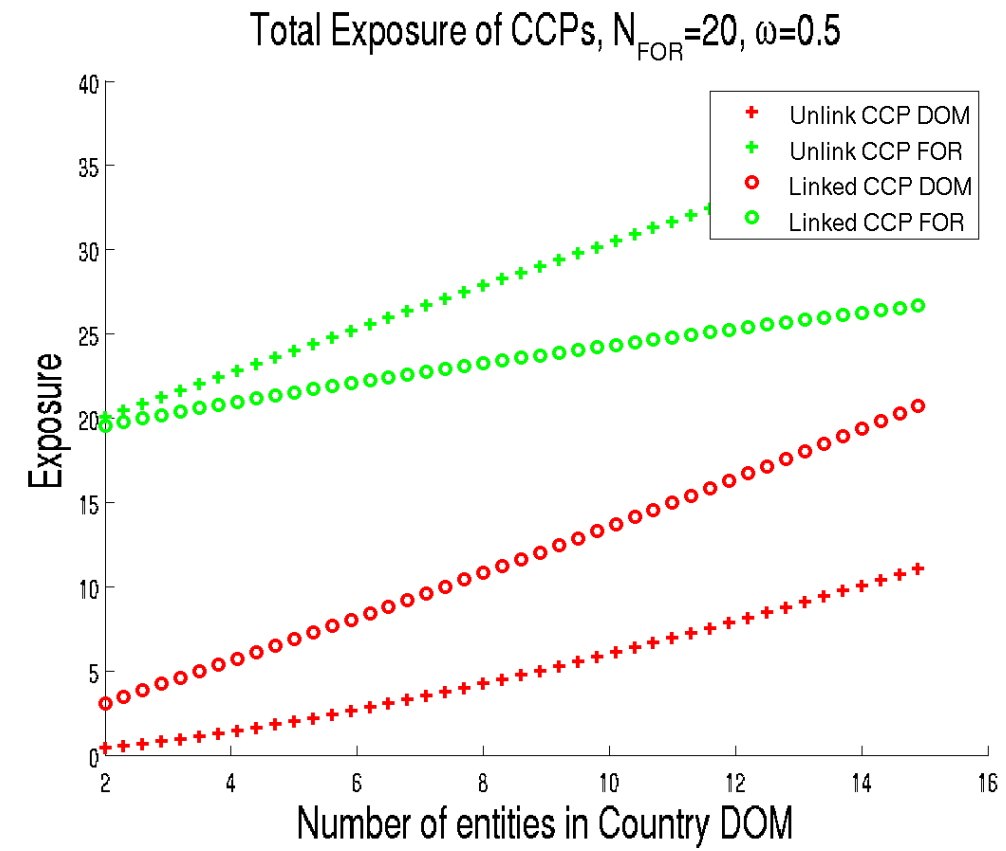

Figure 7: Expected Exposures for CCP DOM and CCP FOR 